\title{
INCIDENCE OF MULTIPLE MYELOMA AMONG CLEANUP WORKERS OF THE CHORNOBYL ACCIDENT AND THEIR SURVIVAL
}

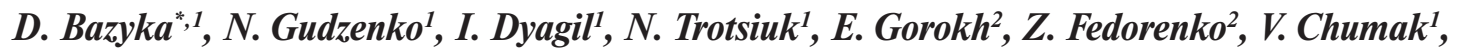 \\ E. Bakhanova ${ }^{1}$, I. Ilienko ${ }^{1}$, A. Romanenko ${ }^{1}$ \\ ${ }^{1}$ National Research Center for Radiation Medicine of the National Academy of Medical Sciences \\ of Ukraine, Kyiv 04050, Ukraine \\ ${ }^{2}$ National Cancer Institute, Kyiv 03022, Ukraine
}

\begin{abstract}
The study presents the updated data on the multiple myeloma (MM) incidence in Ukrainian cleanup workers after the Chornobyl accident and their survival. The epidemiological analysis is based on the extended follow-up period to identify new MM cases for higher statistical power and to collect additional data on the disease course and outcome for the survival analysis. The objective of the study was to analyze the MM incidence and survival in Chornobyl cleanup workers in 1996-2013 in comparison with the national MM statistical data. Materials and Methods: A study cohort consisted of 152,520 male cleanup workers resided in one of 6 regions of Ukraine or Kyiv city and registered in the Ukrainian State Chornobyl Registry (SChR). The Cohort Database was linked to the Ukrainian National Cancer Registry (NCR) Database to identify MM cases and to analyze MM incidence in 19962013. Standardized incidence ratios (SIR) for MM over the period 1996-2013 were calculated as compared to the general population of Ukraine. A 10-year lag period (when incident cases are not considered radiation-related) was applied. One-year and 5-year cause-specific survival of MM cases were calculated as percentage of those who were alive correspondingly for 1 or 5 years after diagnosis among overall diagnosed. By the moment, the 5-year survival rate either for the sub-period 2008-2013 or for the whole study period 1996-2013 cannot be determined. Vital status data were updated according to the recent SChR and NCR information. Results: 75 MM cases diagnosed in 1986-2013 were identified in the studied cohort. 69 of them were included to the incidence analysis considering a $\mathbf{1 0}$-year lag period. While the incidence over 15 years after the accident did not differ significantly from the corresponding rate in general population of Ukraine, a tendency to increase was seen in the period from 16 to 21 years after the accident, and significantly increased SIR estimate was revealed for 2008-2013 (SIR 1.86, 95\% confidence interval (CI) 1.27-2.44). The highest incidence was detected in 2008-2013 among cohort members diagnosed over the age of 50 years mostly due to the significant excess among those aged 60-69 (SIR 2.46, 95\% CI 1.32-3.59). Survival rates in cleanup workers were shown to be higher than in the general population of Ukraine (73.9\% and up to $65.0 \%$, respectively). Conclusions: SIR for the $2008-$ 2013 period, 22-27 years after the accident, demonstrated the significant excess of MM incidence among male cleanup workers. Survival of MM cases is higher in cleanup workers in comparison with that in general population. This article is a part of a Special Issue entitled "The Chornobyl Nuclear Accident: Thirty Years After".
\end{abstract}

Key Words: Chornobyl accident, cleanup workers, multiple myeloma, incidence, survival.

Multiple myeloma (MM) represents a malignancy from mature B-cell lymphocytes that may appear after the exposure to ionizing radiation. The effect of ionizing radiation is still debatable although some evidence was received from the studies of population groups irradiated due to the accidents, professional or medical needs.

Potential causative role of ionizing radiation in $\mathrm{MM}$ induction was shown in the mortality studies of survivors after A-bombing in Japan [1], although incidence study among the Life Span Study cohort (1950-2001) did not confirm these findings [2]. However, the MM incidence was higher among nuclear industry workers than in the general population. The 15-country collaborative study of cancer risk among radiation workers reported about a marginally significant association for MM [3]. Also the study completed by IARC in 1995 among nuclear workers from facilities in the USA, the UK and Canada found weak but statistically significant association between occupational exposure and the risk of MM (one-sided

Submitted: June 29, 2016.

*Correspondence: E-mail: bazyka@yahoo.com

Abbreviations used: MM - multiple myeloma; NCR - National Cancer Registry; NRCRM - National Research Center for Radiation Medicine; RBM - red bone marrow; SChR - State Chornobyl Registry; SIR - standardized incidence ratio. $p$ value $=0.037 ; 44$ deaths) [4]. A positive association between MM and low level doses of external exposure increasing with the age at exposure was shown among nuclear workers at the US Department of Energy facilities [5]. MM was in excess in the Hanford Nuclear Reservation cohort [6]. A case-control study of MM risk and internal uranium dose among workers at the Oak Ridge Gaseous Diffusion Plant showed weak statistically significant association [7]. In the French cohort of nuclear workers an excess of borderline statistical significance for MM was observed [8]. Despite the observed healthy worker effect in general for MM there was an indication of an increasing trend in risk with external dose $(p=0.06)$.

On the other hand, some recent studies in Czech uranium miners [9] and in patients treated with pelvic radiotherapy [10] have shown no excess of MM. Highly exposed due to treatment were shown to have higher risk of MM incidence although not significantly. In Ukraine the MM incidence in 2002-2013 was 1.0-1.2 per 100,000 population, it increased significantly with age and had non-homogenous time trends. The incidence of MM was higher in males than in females. First year mortality in newly diagnosed MM patients in Ukraine in 2002-2013 decreased ranging from 41.0 to $34.6 \%$ with a substantially higher portion of deceased within 
1 year among males. Correspondingly, 1 -year survival increased with time and ranged from 59.0 to $65.4 \%$ [11] .

After the Chornobyl accident, hundreds of thousands of cleanup workers (predominantly males) were irradiated while working in the territories around the nuclear power plant. Hematological malignancies were among the first expected outcomes in exposed population that motivated scientific community to initiate widespread investigations.

The study on MM in a range of malignant hematological disorders in Chornobyl cleanup workers provides an opportunity to verify dependencies explored earlier and to get additional data on MM appearance after low dose/dose rate radiation exposure.

The objective of the study was to analyze standardized incidence ratio (SIR) of MM and survival in a cohort of male cleanup workers in 1996-2013.

\section{MATERIALS AND METHODS}

The study cohort was assembled basing on the State Chornobyl Registry (SChR) and consisted of 152,520 male cleanup workers resided 6 oblasts of Ukraine (Cherkassy, Chernihiv, Dnipropetrovsk, Donetsk, Kharkiv, Kyiv) and Kyiv city. Periodically updated personal data (demographic information and results of annual health checks) were transferred from the SChR Database to the cohort file at the National Research Center for Radiation Medicine (NRCRM) [12,13]. The cohort includes males who were exposed in young or middle age predominantly. About $70 \%$ were younger than 40 at first exposure (mean age 34.5 years) (Table 1 ).

Table 1. Main characteristics of the study cohort of Ukrainian liquidators and MM cases identified in this cohort in 1996-2013

\begin{tabular}{|c|c|c|c|c|}
\hline \multirow[b]{2}{*}{$\begin{array}{l}\text { Age group, } \\
\text { years }\end{array}$} & \multicolumn{2}{|c|}{$\begin{array}{l}\text { Cohort under follow up, } \\
\text { number of subjects, } \mathrm{n}(\%)\end{array}$} & \multicolumn{2}{|c|}{$\begin{array}{c}\text { MM cases, } \\
\text { number of subjects, n (\%) }\end{array}$} \\
\hline & $\begin{array}{l}\text { Attained age } \\
\text { at registration } \\
\text { in the } \mathrm{SChR}\end{array}$ & $\begin{array}{c}\text { Age at first } \\
\text { exposure }\end{array}$ & $\begin{array}{l}\text { Attained age } \\
\text { at registration } \\
\text { in the SChR }\end{array}$ & $\begin{array}{l}\text { Age at first } \\
\text { exposure }\end{array}$ \\
\hline$<30$ & $21,226(13.9)$ & $43,358(28.4)$ & $5(7.2)$ & $8(11.6)$ \\
\hline $30-39$ & $55,448(36.4)$ & $62,866(41.2)$ & $20(29.0)$ & 32 (46.4) \\
\hline $40-49$ & $42,220(27.7)$ & 25,238 (16.5) & $21(30.4)$ & $21(30.4)$ \\
\hline $50-59$ & 21,953 (14.4) & 8381 (5.5) & $16(23.2)$ & $3(4.3)$ \\
\hline $60-69$ & $9666(6.3)$ & $773(0.5)$ & $7(10.1)$ & 0 \\
\hline$\geqslant 70$ & 1578 (1.0) & 0 & 0 & 0 \\
\hline Unknown & $429(0.3)$ & $11,899(7.8)$ & 0 & $5(7.2)$ \\
\hline Total & $152,520(100)$ & $152,520(100)$ & 69 (100) & 69 (100) \\
\hline $\begin{array}{l}\text { Mean age, } \\
\text { years }( \pm S D)\end{array}$ & $41.1( \pm 11.1)$ & $34.5( \pm 8.8)$ & $45.1( \pm 10.9)$ & $38.2( \pm 0.9)$ \\
\hline
\end{tabular}

The study on MM among cleanup workers was initiated within the framework of the joint U.S.-Ukrainian study on leukemia and other hematological disorders. At that time, data on patients with MM diagnosed in the period 1986-2000 were identified by search in local and state hematological departments. Further investigation was carried out by the NRCRM group. The Cohort Database was linked to the Ukrainian National Cancer Registry (NCR) Database to identify MM cases diagnosed in the cohort in 2001-2013.

Cases diagnosed before 2001 were reviewed by the International Diagnostic review panel and classified using the International Staging System [12]. For cases diagnosed in 2001-2013 a validation procedure was performed using the medical records and pathology information obtained from the NCR and reviewed by the NRCRM experts.

Individual doses to red bone marrow (RBM) due to subject's external exposure were reconstructed retrospectively using a time-and-motion RADRUE method, which was developed for studies of the Chornobyl accident consequences by the international group of experts [14]. We tabulated the demographic characteristics of verified MM cases and calculated crude rates as well as SIR for cleanup workers using the Ukrainian population statistics. We calculated trends in 1- and 5-year survival for MM over the period from 1996 to 2013. To analyze at least 1 -year survival of patients we controlled the vital status of all identified cases until and over 2014.

Flow cytometry analysis was performed using 2-laser flow cytometer FACScalibur (Becton Dickinson, USA) equipped with two lasers with excitation waves length of 488 and $635 \mathrm{~nm}$. Whole blood and bone marrow samples were stained using a standard BD procedure with combinations of monoclonal antibodies in two- and three-color assay. Panel of monoclonal antibodies (all from Becton Dickinson) included: antiCD45/14; anti-CD5/10/19; anti-CD33/7; anti-CD13/ HLADR; anti-CD3/4/8; anti-CD45/56/138; antiCD25/38; anti-CD19/20/23; anti-CD34/38. At batch analysis the main B-cell subsets were identified using the standard operational procedure. During batch analysis three-color staining CD45/SSC graphs were used for setting lymphoid cell discrimination and at the next stage CD56+138+ cell subset was identified at twodimensional graph of CD45+SSC low gated cells.

\section{RESULTS}

75 cases of MM were identified in the studied cohort in 1986-2013. 6 cases diagnosed in 1986-1995 were not included into analysis according to the applied 10-year lag period. SIR were calculated for $69 \mathrm{MM}$ cases identified in the cohort during the follow-up period 1996-2013. The demographic characteristics of these cases are given in Table 1 together with the characteristics of the cohort. Mean attained age of the identified MM cases was 45.1 , and it was 41.1 for cleanup workers at whole, about half of them were younger than 40 at time of registration in SChR. MM cases in average did not differ from the whole cohort members in age they started participating in cleanup (mean age at first exposure was 38.2 and 34.5 years, correspondingly). Subjects first exposed before age 40 comprise respectively 58.0 and $69.9 \%$. All but one cases were aged over 40 at the time of their diagnosis, median age at diagnosis was 58 years.

Clinical data for each case and biological material samples (peripheral blood, bone marrow or trepanobiopsy) for most of them were reviewed to confirm or clarify the diagnosis. Each of the identified cases diagnosed in 1996-2006 has undergone the diagnosis verification procedure by the independent Diagnostic Review Panel of qualified hematologists and hematopathologists from the USA, France, the United Kingdom and Ukraine. The Panel's consensus opinion was the 
Review conclusion [15]. High quality of MM diagnostics was recognized due to the high percentage of morphologically confirmed MM cases in general population of Ukraine (98\%) and the confirmation rate achieved after the international diagnostic review of MM cases diagnosed in 1996-2006, when 5 diagnoses of 25 reviewed cases were not confirmed, 2 of them just due to the lack of diagnostic material samples.

According to the performed analysis, MM incidence rate in the studied cohort of cleanup workers did not differ significantly from the corresponding rate in the general population of Ukraine for the period from 10 to 15 years after the accident; a tendency to increase was demonstrated in the period from 16 to 21 years after the accident, and significantly increased rates were revealed in 2008-2013 (SIR 1.86, 95\% confidence interval (Cl) 1.27-2.44), resulting in the excess during the whole study period (Table 2). Persons diagnosed over the age of 50 were more vulnerable mostly due to the significant excess in 2008-2013 among those aged 60-69 (SIR $2.46,95 \% \mathrm{Cl} 1.32-3.59)$. Other subgroups of those older than 50 at diagnosis ( $50-59$, and $\geqslant 70$ ) haven'tshown any significant excess either during the whole study period or by sub-periods.

Table 2. SIR for MM in the cohort of male cleanup workers in 1996-2013

\begin{tabular}{|c|c|c|c|c|c|}
\hline \multirow{2}{*}{$\begin{array}{l}\text { Period of obser- } \\
\text { vation }\end{array}$} & \multirow{2}{*}{$\begin{array}{c}\text { Person- } \\
\text { years } \\
\text { of obser- } \\
\text { vation }\end{array}$} & \multicolumn{2}{|c|}{$\begin{array}{l}\text { Number } \\
\text { of cases }\end{array}$} & \multirow{2}{*}{$\begin{array}{c}\text { Crude } \\
\text { rate } \\
\text { per } \\
105 \\
\end{array}$} & \multirow{2}{*}{ SIR (95\% CI) } \\
\hline & & $\begin{array}{c}\text { ob- } \\
\text { served }\end{array}$ & $\begin{array}{l}\text { expec- } \\
\text { ted }\end{array}$ & & \\
\hline 1996-2001 & 823,198 & 13 & 13.2 & 1.58 & $0.98(0.45-1.52)$ \\
\hline 2002-2007 & 707,428 & 17 & 15.7 & 2.4 & $1.08(0$ \\
\hline $2008-2013$ & 593,309 & 39 & 21.0 & 6.6 & $1.86(1.27-2.44)$ \\
\hline $1996-2013$ & $2,123,934$ & 69 & 49.9 & 3.24 & $1.38(1.06-1.71)$ \\
\hline \multirow{3}{*}{$\begin{array}{l}\text { Age at diagnosis } \\
<50 \\
\geqslant 50\end{array}$} & & & & & \\
\hline & 983,0 & 10 & 9.7 & 1.02 & $1.03(0.39-1.67)$ \\
\hline & $1,140,843$ & 59 & 37.9 & 5.17 & $1.56(1.16-1.95)$ \\
\hline
\end{tabular}

The RBM doses due to external irradiation were reconstructed for 31 of 69 identified MM cases. Dose values were in the range from 0.1 to $2893.6 \mathrm{mGy}$. In 8 (25.8\%) cases the RBM doses were higher than 100 mGy. We plan to continue dose reconstruction for identified MM cases and for corresponding controls selected within the study cohort to analyze possible radiation risks.

As to identified cases (Table 3), 1-year survival indices were shown to be higher than for those diagnosed in the general population of Ukraine $(73.9 \%$ and up to $65 \%$ correspondingly) [11]. Greater survival in cleanup workers may result from better medical service in population groups affected by the Chornobyl accident comparing with the general population. One-year survival among the cases diagnosed before age 50 was expectedly higher than in older cases but not significantly.

By the end of observation period 42 (60.9\%) patients were deceased (Table 3). Analysis of the clinical course of the cases showed that the majority of the MM diagnoses were established at late stages of disease with an involvement of the bone system, kidney, hemorrhagic syndrome due to the high level of abnormal proteins in the blood and urine. All of these patients were diagnosed in 1997-2010. Treatment strategies included monochemotherapy and radiotherapy.
Table 3. 1-year and 5-year survival of MM cases by sub-period of observation and age at diagnosis

\begin{tabular}{lcccc}
\hline \begin{tabular}{c} 
Period of obser- \\
vation (cases di- \\
\multicolumn{1}{c}{ agnosis) }
\end{tabular} & $\begin{array}{c}\text { Number } \\
\text { of cases } \\
\text { (cases de- } \\
\text { ceased over } \\
2013, \%)\end{array}$ & $\begin{array}{c}\text { Mean age } \\
\text { (median } \\
\text { age) at di- } \\
\text { agnosis, } \\
\text { years }\end{array}$ & $\begin{array}{c}\text { 1-year sur- } \\
\text { vival, } \mathrm{n}(\%)\end{array}$ & $\begin{array}{c}\text { 5-year sur- } \\
\text { vival, } \mathrm{n}(\%)\end{array}$ \\
\hline $1996-2001$ & $13(92.3)$ & $54(57)$ & $9(69.2)$ & $2(15.4)$ \\
$2002-2007$ & $17(76.5)$ & $54(53)$ & $14(82.4)$ & $6(35.3)$ \\
$2008-2013$ & $39(43.6)$ & $62(62)$ & $28(71.8)$ & n.d. ${ }^{*}$ \\
$1996-2013$ & $69(60.9)$ & $58(58)$ & $51(73.9)$ & n.d. \\
$\begin{array}{l}\text { Age at diagnosis } \\
<50\end{array}$ & $10(70.0)$ & $45(46)$ & $8(80)$ & n.d. \\
$\geqslant 50$ & $59(59.3)$ & $61(60)$ & $44(74.6)$ & n.d. \\
\hline
\end{tabular}

Note: *n.d. - non-determinable.

In the later period from 2010 to 2013, case diagnostics improved and patients were diagnosed at earlier stages of the disease. Proper diagnosis of solitary myeloma and MM without marked changes in bone tissue became possible. MM diagnosis in 8 cases before 2000 was established using classical clinical criteria by the International Review Group. A certain progress was achieved after implementation of flow cytometry. To investigate bone marrow and peripheral blood clonal proliferative plasma cell pool the immunophenotyping was performed for 22 cases. Typical MM cells were CD38+ and CD56+ with low expression of B-lineage antigens CD19, CD20, CD23, CD22 and early antigens like CD10. MM phenotype has to be differentiated with the changes in monoclonal gammopathy of undetermined significance and NK-cell leukemia. For such cases CD56/45/138 staining was implemented resulting in an increased quality of diagnostics (Figure). Treatment of MM became more intensive with the use of modern protocols and subsequent autologous stem cell transplantation in patients younger than 65 years. This approach can significantly improve the effectiveness of treatment and patients' quality of life. Elongation of MM cases survival is also associated with the advent of effective therapeutic drugs for this group of patients.

\section{DISCUSSION}

This study demonstrates increased incidence rates of MM in a cohort of Chornobyl cleanup workers in a period up to 28 years after the accident as compared to the general population of Ukraine. Strength of this study is in the use of updated cohort ensuring statistical significance of the results [12]. These data are in conformity with previously obtained data [16], indicating an MM incidence increase with time since exposure. Our results are consistent in general with conclusions obtained in other long-term studies in nuclear workers, i.e. in a mortality study performed in a pooled cohort of 119,195 U.S. nuclear workers at five nuclear facilities (Hanford site, Idaho National Laboratory, Oak Ridge National Laboratory, Savannah River site and at the Portsmouth Naval Shipyard). The cohort was followed at the start of the workers beginning their radiation work (at earliest, between 1944 and 1952) through 2005. The dose dependent excess relative risk was shown for MM (ERR per $10 \mathrm{mSv}$ was 3.9\% (95\% Cl 0.60-9.5\%) [17]. Unlike this study our aim was to reveal just incidence rates and survival during the study period. At the same time, planned reconstruction of RBM doses 
for identified cases and matched controls will provide the possibility of dose-dependent risk estimates.
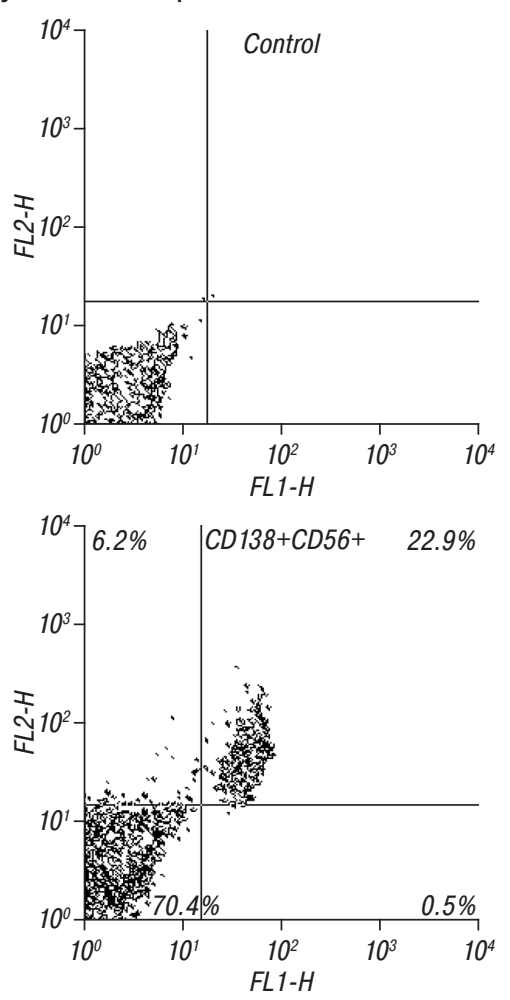

(b)

Figure. Expression of CD138 and CD56 on MM cells: a) control staining; $b$ ) staining with CD138-FITC and CD56-PE

The uncertainties in our study as well as in other long-term studies are related to quality of diagnostic approaches used for case validation which are improving with time. Our group tried to reduce the influence of such factors at the first stage of the study (19862000), when the NCR data were not available, by inviting the International Review Group for case diagnostic verification. Later cases were diagnosed by the upto-date approach that enabled one to differentiate benign monoclonal B-lymphocytosis, unspecified monoclonal gammopathies, and other mature B-cell disorders. Such an approach is recommended by other researchers [18-20]. Hence, cases registered in the NCR were diagnosed with the up-to-date approaches. However, influence of differences in diagnostics quality on MM incidence in exposed and not-exposed groups remains unclear. This study hasn't revealed significant differences in the MM natural course influencing timely diagnosis.

This study also demonstrated better survival rates for cleanup workers in comparison with the general population of Ukraine. This difference could be related to the better health care and treatment opportunities in radiation exposed subjects.

Our study provides the informative base for the consequent case-control study on dose dependent MM risk estimates. Next steps in our research will be the following: incidence density sampling of the controls in the study cohort accounting for the attained age and region of residency; dose reconstruction for all identified cases and corresponding controls with
RADRUE method; applying the statistical models for $\mathrm{MM}$ risk evaluation.

\section{CONCLUSIONS}

The MM incidence in the male Chornobyl cleanup workers in 1996-2013 significantly exceeds the corresponding rate in the general population of Ukraine with the highest SIR for the latest period of observation, 2008-2013. Observed MM incidence excess was due to the excess in those older than 50 at diagnosis mostly due to patients aged 60-69. Survival of MM patients in the male cleanup workers cohort exceeds that in the general population of the corresponding gender and age. It tends to be higher in the youngest men and decreases with increasing age. A case-control study needs to be carried out to confirm dependencies in MM incidence on radiation dose if exist.

\section{ACKNOWLEDGEMENTS}

This research was partly supported by the Intramural Research Program of the U.S. National Cancer Institute. Authors are greatly thankful to International Hematology Review Panel members - Dr. B. Bain (Imperial College School of Medicine, Saint Mary's Hospital, UK), Prof. S. Gajdukova (Kyiv Academy of PostGraduate Medical Training, Ukraine), Prof. D. Gluzman (R.E. Kavetsky Institute of Experimental Pathology, Oncology and Radiobiology of the NAS of Ukraine, Ukraine), Dr. P. McPhedran (Yale New Haven Hospital, USA), Dr. L.-A. Peterson (Feinberg Medical School of Northwestern University, USA) for their expertise and invaluable advice. We would like to acknowledge the significant efforts of Drs. S.C. Finch and R. Reiss for their preliminary expertise of diagnostic material and preparing the International Diagnostic Review. We are especially grateful to the local hematology staff for their diligent work of preparing clinical records and biological materials for case ascertainment as well as the local technical staff for their enormous work on tracing and contacting cases.

\section{REFERENCES}

1. Pierce DA, Shimizu Y, Preston DL, et al. Studies of the mortality of atomic bomb survivors. Report 12, Part I. Cancer: 1950-1990. Radiat Res 1996; 146: 1-27.

2. Hsu WL, Preston DL, Soda M, et al. The incidence of leukemia, lymphoma and multiple myeloma among atomic bomb survivors: 1950-2001. Radiat Res 2013; 179: 361-82.

3. Cardis E, Vrijheid M, Blettner M, et al. The 15-country collaborative study of cancer risk among radiation workers in the nuclear industry: estimates of radiation-related cancer risks. Radiat Res 2007; 167: 396-416.

4. Cardis E, Gilbert ES, Carpenter L, et al. Effects of low doses and low dose rates of external ionizing radiation: cancer mortality among nuclear industry workers in three countries. Radiat Res 1995; 142: 117-32.

5. Wing S, Richardson D, Wolf S, et al. A case control study of multiple myeloma at four nuclear facilities. Ann Epidemiol 2000; 10: 144-53.

6. Dement JM, Ringen K, Welch LS, et al. Mortality of older construction and craft workers employed at Department of Energy (DOE) nuclear sites. Am J Ind Med 2009; 52: 671-82. 
7. Yiin JH, Anderson JL, Daniels RD, et al. A nested casecontrol study of multiple myeloma risk and uranium exposure among workers at the Oak Ridge Gaseous Diffusion Plant. Radiat Res 2009; 171: 637-45.

8. Telle-Lamberton M, Samson E, Caër S, et al. External radiation exposure and mortality in a cohort of French nuclear workers. Occup Environ Med 2007; 64: 694-700.

9. Rericha V, Kulich M, Rericha R, et al. Incidence of leukemia, lymphoma, and multiple myeloma in Czech uranium miners: a case - cohort study. Environ Health Perspect 2006; 114: 818-22.

10. Wright JD, St Clair CM, Deutsch I, et al. Pelvic radiotherapy and the risk of secondary leukemia and multiple myeloma. Cancer 2010; 116: 2486-92.

11. National Cancer Registry of Ukraine [homepage on the Internet]. Kyiv: National Cancer Registry of Ukraine [cited 2016 Jun 29]. Available from: http://www.ncru.inf.ua/publications/index.htm.

12. Romanenko A, Bebeshko V, Hatch $\mathbf{M}$, et al. The Ukrainian-American study of leukemia and related disorders among Chornobyl cleanup workers from Ukraine: I. Study methods. Radiat Res 2008; 170: 691-7.

13. Zablotska LB, Bazyka D, Lubin JH, et al. Radiation and the risk of chronic lymphocytic and other leukemias among Chornobyl cleanup workers. Environ Health Perspect 2013; 121: 59-65.

14. Kryuchkov V, Chumak V, Maceika E, et al. RADRUE method for reconstruction of external photon doses for Cher- nobyl liquidators in epidemiological studies. Health Phys 2009; 97: 275-98

15. Dyagil I, Adam M, Beebe GW, et al. Histologic verification of leukemia, myelodysplasia, and multiple myeloma diagnoses in patients in Ukraine, 1987-1998. Int J Hematol 2002; 76: 55-60.

16. Bazyka DA, Gudzenko NA, Dyagil IS, et al. Multiple myeloma among Chornobyl accident cleanup workers - state and perspectives of analytical study. Probl Radiac Med Radiobiol 2013; (18): 169-72.

17. Schubauer-Berigan MK, Daniels RD, Bertke SJ, et al. Cancer mortality through 2005 among a pooled cohort of U.S. nuclear workers exposed to external ionizing radiation. Radiat Res 2015; 183: 620-31.

18. Junxun L, Juan L, Xiuzhen T, et al. Comparing five diagnostic criteria for multiple myeloma: a retrospective study of 227 cases. Tumori 2014; 100: 207-13.

19. Alley CL, Wang E, Dunphy CH, et al. Diagnostic and clinical considerations in concomitant bone marrow involvement by plasma cell myeloma and chronic lymphocytic leukemia/monoclonal B-cell lymphocytosis: a series of 15 cases and review of literature. Arch Pathol Lab Med 2013; 137: 503-17.

20. Matsue K, Matsue Y, Kumata K et al. Quantification of bone marrow plasma cell infiltration in multiple myeloma: usefulness of bone marrow aspirate clot with CD138 immunohistochemistry. Hematol Oncol 2016; doi: 10.1002/hon.2300 [Epub ahead of print]. 